\title{
Consumo, digestibilidade e parâmetros ruminais em ovinos recebendo silagens e fenos em associação à palma forrageira
}

\author{
Intake, digestibility and ruminal measures in sheep feed silage and hay in association \\ with cactus pear
}

\author{
WANDERLEY, Walmir Lima ${ }^{1}$; FERREIRA, Marcelo de Andrade ${ }^{2 *}$; BATISTA, \\ Ângela Maria Vieira ${ }^{2}$; VÉRAS, Antonia Sherlânea Chaves ${ }^{2}$; BISPO, Safira Valença ${ }^{3}$; \\ SILVA, Fabiana Maria da ${ }^{2}$; Viviany Lúcia Fernandes dos Santos $^{2}$
}

\footnotetext{
${ }^{1}$ Instituto Federal de Pernambuco, Barreiros, Pernambuco, Brasil.

${ }^{2}$ Universidade Federal Rural de Pernambuco, Recife, Pernambuco, Brasil.

${ }^{3}$ Universidade Federal da Paraíba, Deparatmento de Zootecnia, Areia, Paraíba, Brasil.

*Endereço para correspondência: ferreira@dz.ufrpe.br
}

\section{RESUMO}

O experimento foi realizado com o objetivo de avaliar o efeito da associação de silagens de girassol e sorgo; fenos de leucena, guandu e capim-elefante, com palma forrageira, sobre o consumo, digestibilidade aparente dos nutrientes e parâmetros ruminais em ovinos sem padrão racial definido, com fístulas no rúmen. Foram utilizados cinco ovinos com peso corporal médio de $30 \mathrm{~kg}( \pm 0,3)$, distribuídos em quadrado latino $5 \times 5$. Os consumos de matéria seca, matéria orgânica, proteína bruta, carboidratos totais, carboidratos não-fibrosos, nutrientes digestíveis totais, fibra em detergente neutro ( $\%$ peso vivo), digestibilidade aparente da proteína bruta e carboidratos não-fibrosos não foram influenciados pela associação dos alimentos. O consumo de extrato etéreo foi superior no tratamento com silagem de girassol em relação à silagem de sorgo e aos fenos. O consumo de fibra em detergente neutro ( $\mathrm{kg} / \mathrm{dia})$ foi superior para o tratamento com feno de capim-elefante em relação à silagem de girassol e semelhante aos demais tratamentos. A digestibilidade aparente da matéria seca para a silagem de sorgo foi superior quando comparada aos fenos de leucena e capim elefante. Não foi observada diferença significativa para os valores de $\mathrm{pH}$ e concentração de amônia ruminal para os tratamentos nos diferentes tempos de coleta. A associação da palma forrageira com silagens e fenos não altera o consumo de matéria seca e energia. Silagens de sorgo e girassol e fenos de leucena, guandu e de capim elefante associados à palma forrageira apresentam-se como uma boa alternativa alimentar para ovinos na região semiárida do Nordeste brasileiro.

Palavras-chaves: amônia ruminal, carboidratos não-fibrosos, consumo de nutrientes, nutrientes digestíveis totais, opuntia

\section{SUMMARY}

The aim of the present experiment was to assess the effect of the association of the spineless cactus with sunflower silage, sorghum silage, leucena hay, pigeon pea hay or elephant grass hay on intake, apparent digestibility of nutrients and ruminal measures in mixed breed sheep, with fistulas in the rumen. Five sheep with a mean body weight of $30 \mathrm{~kg}( \pm 0,3)$, were distributed in $5 \times 5$ Latin squares. Intake of dry matter, organic matter, crude protein, total carbohydrates, total digestible nutrients (in $\mathrm{kg}$ /day), neutral detergent fiber (in \% of live weight), apparent digestibility of crude protein and non-fiber carbohydrates were not influenced by the association of spineless cactus and the silages or hays. Ether extract intake was greater for the elephant grass hay treatment in comparison to sunflower silage and similar to the sorghum silage and hays. Apparent digestibility of dry matter, organic matter, ether extract, neutral detergent fiber and total carbohydrates was not influenced by the association of spineless cactus and silages or hays. Apparent digestibility of dry matter for sorghum silage was higher in comparison to the 
leucena hay and elephant grass hay. There was no significant difference between $\mathrm{pH}$ and ruminal ammonia concentration for the treatments at different sampling times. The association of spineless cactus and silages or hays did not alter dry matter intake and energy. Sorghum silages and sunflower and leucena, pigeon pea and elephant grass hay associated the spineless cactus show a good food alternative to sheep in semiarid region of the northeastern Brazil.

Keywords: ruminal ammonium, non-fiber carbohydrate, nutrient intake, total digestible nutrients, opuntia

\section{INTRODUÇÃO}

A estacionalidade da produção de forragens em regiões semiáridas é provocada pela baixa precipitação e distribuição irregular das chuvas, o que compromete o desempenho animal. A palma forrageira é uma cultura que apresenta aspecto fisiológico especial quanto à absorção, aproveitamento e perda de água, suporta prolongados períodos de estiagem, por isso, se adapta bem às condições adversas do semiárido (SILVA \& SANTOS, 2006). Em função da adequação ao clima seco e quente do semiárido brasileiro é uma alternativa para a alimentação animal na região (MENEZES et al., 2008).

Segundo Ferreira et al. (2009), a palma forrageira apresenta alta palatabilidade e grandes quantidades podem ser voluntariamente consumidas. No entanto, embora seja uma excelente fonte de CNF (importante fonte de energia para os ruminantes), a palma forrageira apresenta baixos teores de MS, FDN e o teor de PB é insuficiente para o adequado desempenho animal, o que faz necessária a associação da palma com outros alimentos.

Apesar do baixo conteúdo de matéria seca da palma forrageira, já foi demonstrado que, quando a relação
FDN:CNF segue as recomendações propostas pelo NRC (2001) o teor de água desta forrageira não causa qualquer tipo de distúrbio digestivo nos animais (BISPO et al, 2007). Portanto, existe a necessidade de corrigir o déficit de FDN através de fontes de fibra fisicamente efetiva e proteína.

Para suprir a deficiência em fibra da palma, sugere-se a associação desta planta a alimentos que possuam fibra em detergente neutro altamente efetiva como silagens, fenos, e restos de cultura (FERREIRA, 2005).

Dentre as fontes de nitrogênio comumente utilizadas, a ureia tem sido bastante empregada, associada à palma forrageira por ser um composto de fácil aquisição, baixo custo e utilizada pelos micro-organismos, quando na presença de fontes de energia prontamente fermentável no rúmen, para formação de proteína microbiana (CRUZ et al., 2006).

Objetivou-se avaliar o efeito das silagens de sorgo e girassol e os fenos de leucena, feijão guandu e capim-elefante em associação com a palma forrageira sobre o consumo e digestibilidade aparente dos nutrientes, amônia e $\mathrm{pH}$ ruminais e ovinos.

\section{MATERIAL E MÉTODOS}

O experimento foi realizado no Setor de Ovino-caprinocultura do Departamento de Zootecnia da Universidade Federal Rural de Pernambuco. Foram utilizados cinco ovinos mestiços fistulados no rúmen, com peso vivo médio de $30 \mathrm{~kg}$ $( \pm 0,3)$. Os animais foram distribuídos em quadrado latino $5 \times 5$, sendo cinco animais, cinco períodos (sete dias para adaptação e sete dias para coleta de dados e amostras) e cinco tratamentos experimentais. Os animais foram 
mantidos em baias individuais, dotadas de cochos e bebedouros para o controle do consumo de alimentos.

Os tratamentos experimentais consistiram na associação de silagem de sorgo, silagem de girassol, feno de leucena, feno de feijão guandu e feno de capim-elefante com palma forrageira (Tabela 2).

A cultivar de palma forrageira utilizada foi a gigante (Opuntia ficus indica Mill), colhida aos dois anos de idade. e proveniente da própria estação(retirar).

A cultivar de leucena utilizada foi a CNPC 846. Foram colhidos ramos, que mediam no máximo $1 \mathrm{~cm}$ de diâmetro, após o período de frutificação. $\mathrm{O}$ feijão guandu (Cajanus cajan (L.) Millsp.) foi obtido de uma propriedade particular após a colheita das sementes e foi adotado o mesmo critério para confecção do feno de leucena. $\mathrm{O}$ capim elefante (Pennisetum purpureum Scum), Napier, foi fenado após 90 dias do corte de uniformização, a partícula media em torno de $1,5 \mathrm{~cm}$, e foi seco em área de cimento durante dois dias.

Com relação ao girassol foi utilizada a cultivar Catissol 01, colhido antes de atingir o ponto ideal para produção de silagem devido à ocorrência de ataque de pássaros. A cultivar de sorgo utilizada foi a IPA 467-4-2 (IPA 467). Com relação ao sorgo, a colheita $\mathrm{e}$ ensilagem do material foram realizadas quando o grão atingiu o estádio farináceo de maturação. Tanto a planta de sorgo quanto a de girassol foram passadas em máquina forrageira e picadas em tamanho de aproximadamente $3 \mathrm{~cm}$. As silagens e os fenos foram confeccionados na Estação Experimental de Arcoverde, pertencente ao Instituto Agronômico de Pernambuco-IPA e acondicionados em tambores metálicos e armazenados em local protegido da radiação solar direta e das chuvas.

Nas Tabelas 1 e 2 estão apresentadas, respectivamente, a composição nutricional dos ingredientes das dietas experimentais, as proporções dos ingredientes bem como a composição nutricional das dietas totais. $\mathrm{O}$ arraçoamento foi realizado duas vezes ao dia, à vontade, fornecidos $50 \%$ às $7 \mathrm{~h}$ e $50 \%$ às $15 \mathrm{~h}$, na forma de ração completa, de modo a permitir sobras de 5 a $10 \%$ do total da matéria seca fornecida. Durante o período de coleta, amostras de alimentos e das sobras foram recolhidas diariamente. $\mathrm{O}$ consumo foi ajustado por meio de pesagens de alimentos e sobras, toda manhã antes da primeira refeição. No final do experimento, foram feitas amostras compostas por animal e por período, as quais foram secas em estufa de ventilação forçada e moídas em moinho com crivo de $2 \mathrm{~mm}$ de diâmetro para incubação e, posteriormente, em peneira de $1 \mathrm{~mm}$ de diâmetro para análise bromatológica no laboratório de Nutrição Animal do Departamento de Zootecnia da Universidade Federal Rural de Pernambuco.

As determinações de matéria seca (MS), matéria mineral $(\mathrm{MM})$, proteína bruta (PB) e extrato etéreo (EE) foram feitas segundo metodologias descritas por Silva \& Queiroz (2002). Para as determinações das fibras em detergente neutro (FDN) e em detergente ácido (FDA) foi utilizada a metodologia descrita e recomendada pelo fabricante do aparelho $\mathrm{ANKON}^{\circledR}$, mediante a utilização de sacos de tecido-não-tecido (TNT $-100 \mathrm{~g} / \mathrm{m} 2$ ) com dimensões de $4 \times 5 \mathrm{~cm}$, confeccionados no Laboratório de Nutrição Animal.

A coleta de fezes foi realizada diretamente na ampola retal dos animais no $10^{\circ}$ e $12^{\circ}$ dias de cada período experimental, pela manhã e à tarde, cujas amostras foram compostas por animal e por período, as quais foram moídas em moinho e passadas por peneira com crivo de $2 \mathrm{~mm}$. 
ISSN 15199940

Tabela 1. Composição nutricional dos ingredientes das dietas experimentais

\begin{tabular}{|c|c|c|c|c|c|c|c|}
\hline Item & Palma forrageira & $\begin{array}{l}\text { Silagem de } \\
\text { sorgo }\end{array}$ & $\begin{array}{c}\text { Silagem de } \\
\text { girassol }\end{array}$ & $\begin{array}{l}\text { Feno de } \\
\text { leucena }\end{array}$ & $\begin{array}{l}\text { Feno de } \\
\text { guandu }\end{array}$ & $\begin{array}{c}\text { Feno de capim } \\
\text { elefante }\end{array}$ & $\begin{array}{c}\text { Farelo de } \\
\text { soja }\end{array}$ \\
\hline MS (\%) & 9,10 & 29,61 & 21,34 & 86,61 & 88,56 & 87,71 & 87,00 \\
\hline $\mathrm{MO}^{1}$ & 87,43 & 92,11 & 86,44 & 92,90 & 94,91 & 88,40 & 91,52 \\
\hline MM & 12,57 & 7,89 & 13,56 & 7,10 & 5,09 & 11,60 & 8,48 \\
\hline $\mathrm{PB}^{1}$ & 4,92 & 5,34 & 9,12 & 11,69 & 9,32 & 5,58 & 52,00 \\
\hline $\mathrm{EE}^{1}$ & 2,17 & 3,37 & 9,67 & 2,39 & 2,71 & 1,74 & 1,50 \\
\hline $\mathrm{CHT}^{1}$ & 84,13 & 84,14 & 67,63 & 78,70 & 83,02 & 82,27 & 39,62 \\
\hline $\mathrm{FDN}^{1}$ & 31,87 & 64,98 & 49,44 & 66,40 & 69,87 & 77,08 & 15,76 \\
\hline $\mathrm{CNF}^{1}$ & 50,05 & 19,16 & 18,27 & 12,77 & 13,16 & 50,05 & 23,87 \\
\hline $\mathrm{PIDN}^{1}$ & 0,20 & 0,42 & 0,46 & 1,08 & 0,60 & 0,20 & 3,92 \\
\hline FDA $^{1}$ & 20,38 & 41,52 & 42,37 & 51,53 & 55,04 & 54,96 & 14,34 \\
\hline $\mathrm{LIG}^{1}$ & 3,35 & 8,26 & 9,32 & 17,90 & 15,42 & 12,50 & 0,92 \\
\hline
\end{tabular}

$\mathrm{MS}=$ matéria seca; $\mathrm{MO}=$ matéria orgânica; $\mathrm{MM}=$ matéria mineralPB= proteína bruta; $\mathrm{EE}=$ extrato etéreo; $\mathrm{PIDN}=$ proteína insolúvel em detergente neutro; $\mathrm{CHT}=$ carboidratos totais; $\mathrm{CNFp}=$ carboidratos não-fibrosos corrigido para proteína; $\mathrm{FDNp}=$ fibra em detergente neutro corrigida para proteína; $\mathrm{FDA}=$ fibra em detergente ácido; $\mathrm{LIG}=$ lignina; $\mathrm{MM}=$ matéria mineral.

$1_{0} \mathrm{MS}$. 
Tabela 2. Percentual de ingredientes e composição nutricional das dietas

\begin{tabular}{|c|c|c|c|c|c|}
\hline \multirow[b]{2}{*}{ Item } & \multicolumn{5}{|c|}{ Tratamentos (\% na MS total) } \\
\hline & $\begin{array}{l}\text { Silagem de } \\
\text { Sorgo }\end{array}$ & $\begin{array}{c}\text { Silagem de } \\
\text { Girassol }\end{array}$ & $\begin{array}{l}\text { Feno de } \\
\text { Leucena }\end{array}$ & $\begin{array}{l}\text { Feno de } \\
\text { Guandu }\end{array}$ & $\begin{array}{c}\text { Feno de Capim } \\
\text { Elefante }\end{array}$ \\
\hline Palma Forrageira & 59,0 & 62,0 & 63,0 & 61,0 & 60,0 \\
\hline Silagem de Sorgo & 34,4 & - & - & - & - \\
\hline Silagem de Girassol & - & 34,0 & - & - & - \\
\hline Feno de Leucena & - & - & 33,7 & - & - \\
\hline Feno de Guandu & - & - & - & 35,0 & - \\
\hline Feno de Capim Elefante & - & - & - & - & 33,9 \\
\hline Uréia + sulfato de amônio & 1,7 & 1,7 & 1,7 & 1,7 & 1,7 \\
\hline Mistura mineral & 1,6 & 1,6 & 1,6 & 1,6 & 1,6 \\
\hline \multirow[t]{2}{*}{ Farelo de Soja } & 3,3 & 0,7 & 0,0 & 0,6 & 2,8 \\
\hline & \multicolumn{5}{|c|}{ Composição Química } \\
\hline Matéria seca (\%) & 13,0 & 11,84 & 13,61 & 14,01 & 14,2 \\
\hline Matéria orgânica ${ }^{1}$ & 86,3 & 84,2 & 86,4 & 87,1 & 85,0 \\
\hline Matéria mineral $^{1}$ & 13,7 & 15,8 & 13,6 & 12,9 & 15,0 \\
\hline Proteína bruta $^{1}$ & 11,1 & 11,2 & 11,8 & 11,4 & 11,1 \\
\hline Extrato etéreo $^{1}$ & 2,5 & 4,6 & 2,2 & 1,3 & 1,3 \\
\hline Carboidratos totais $^{1}$ & 72,7 & 68,4 & 72,4 & 74,4 & 72,6 \\
\hline Carboidratos não-fibrosos ${ }^{1}$ & 31,0 & 31,8 & 30,0 & 30,5 & 27,0 \\
\hline Fibra em detergente neutro ${ }^{1}$ & 41,6 & 36,7 & 42,5 & 44,0 & 45,6 \\
\hline Fibra em detergente ácido ${ }^{1}$ & 26,5 & 27,1 & 30,2 & 31,7 & 31,0 \\
\hline Lignina $^{1}$ & 4,9 & 5,3 & 8,1 & 7,4 & 6,3 \\
\hline
\end{tabular}


A estimativa de produção de matéria seca fecal foi realizada por meio do indicador matéria seca indigestível (MSi). Alíquotas de $1,0 \mathrm{~g}$ de fenos, silagens, palma e farelo de soja e $0,5 \mathrm{~g}$ de sobras e fezes foram acondicionadas em sacos de TNT $(100 \mathrm{~g} / \mathrm{m} 2)$ e incubadas em um búfalo com fístula no rúmen (animal disponível no setor de Zootecnia), por um período de 144 horas. Após este período os sacos foram retirados, lavados em água corrente até o total clareamento da água, levados à estufa de ventilação forçada $\left(65^{\circ} \mathrm{C}\right)$ por três dias e, posteriormente, colocados em estufa de $105^{\circ} \mathrm{C}$ por uma hora, retirados e acondicionados em dessecador, pesados, e o resíduo obtido considerado $\mathrm{MSi}$ (DETMANN et al. 2001).

Durante os quatro últimos dias de cada período de coleta, foram colhidas amostras de fluido ruminal nos seguintes tempos: imediatamente antes da primeira refeição (correspondente à hora zero) e duas, quatro e seis horas após a primeira refeição. Amostras foram colhidas diretamente via fístula ruminal, filtradas em tecido de algodão para mensuração do $\mathrm{pH}$ e determinação da concentração de $\mathrm{N}_{-} \mathrm{NH}_{3}$. O pH foi medido imediatamente após a colheita do fluido ruminal por meio de um potenciômetro digital. Em seguida, $50 \mathrm{~mL}$ de fluido foram acondicionados em frasco que continha $1 \mathrm{~mL}$ de solução 1:1 de ácido sulfúrico e mantidos a $20^{\circ} \mathrm{C}$ (CABRAL et al., 2008). As amostras de líquido ruminal foram descongeladas para determinação da concentração de $\mathrm{N}-\mathrm{NH}_{3}$ por meio de destilação com solução de hidróxido de potássio $(\mathrm{KOH}) 2 \mathrm{~N}$.

Para estimativa dos carboidratos totais (CHT) foi usada a equação proposta por Sniffen et al. (1992): \%CHT $=100-$ $(\% \mathrm{~PB}+\% \mathrm{EE}+\% \mathrm{MM})$. Para os carboidratos não-fibrosos (CNF), em função da presença de ureia nas dietas, foi usada a fórmula proposta por Hall (2000) $\mathrm{CNF}=100-[(\% \mathrm{~PB}-\% \mathrm{~PB}$ derivada da ureia $+\%$ de ureia) $+\%$ FDN cp $+\%$ EE $+\%$ cinzas]. Para os cálculos dos nutrientes digestíveis totais (NDT), foi utilizada a equação proposta por Sniffen et al (1992): \%NDT = Consumo de NDT/Consumo de MS. O consumo de NDT foi estimado pela formula: CCHTdigestíveis $+\mathrm{CPB}$ digestível $+2,25 *$ CEE digestível.

Os dados foram submetidos à análise de variância, mediante a utilização do programa SAEG (Sistema de Análises Estatísticas e Genéticas) da Universidade Federal de Viçosa (UFV, 2001). Para comparação das médias foi utilizado o teste de Tukey com nível de significância de $1 \%$. O seguinte modelo foi utilizado nas análises:

$\mathrm{y}_{\mathrm{ijk}}=\mu+\mathrm{T}_{\mathrm{i}}+\mathrm{P}_{\mathrm{j}}+\mathrm{A}_{\mathrm{k}}+\mathrm{e}_{\mathrm{ijk}}$

Em que:

$\mu$ é a média do experimento;

$\mathrm{T}_{\mathrm{i}}$ é o efeito do tratamento $\mathrm{i}$;

$\mathrm{P}_{\mathrm{j}}$ é o efeito do período $\mathrm{j}$;

$\mathrm{A}_{\mathrm{k}}$ é o efeito do animal $\mathrm{k}$;

$\mathrm{e}_{\mathrm{ijk}}$ é o erro experimental;

sendo $\mathrm{i}, \mathrm{j}, \mathrm{k}=1,2,3,4,5$.

\section{RESULTADOS E DISCUSSÃO}

Não foi observada diferença significativa $(\mathrm{P}>0,01)$ para consumo de matéria seca entre os tratamentos, independentemente da forma expressa, com médias de $0,968 \mathrm{~kg} / \mathrm{dia} ; 3,05 \%$ PV e $72,58 \mathrm{~g} / \mathrm{kg}^{0,75}$ (Tabela 3). Os principais fatores que afetam o consumo de matéria seca tais como, as condições ambientais, o peso vivo e o manejo não foram alterados. Apesar dos diferentes volumosos utilizados houve pouca alteração na composição das dietas, principalmente $\mathrm{PB}$ e FDN. Um fator que poderia ter contribuído para esse comportamento foi a alta proporção de 
palma em todos os tratamentos, em torno de $61 \%$, alimento que apresenta alta palatabilidade e uma vez que o fornecimento das dietas foi na forma de ração completa, possíveis efeitos negativos dos diferentes volumosos sobre o consumo foram diluídos. Bispo et al. (2007), quando utilizaram até 56\% de inclusão de palma na dieta de ovinos verificaram consumos médios de MS de (966,75g/dia e 3,42\% PV).

A proporção de carboidratos nãofibrosos e FDN nas dietas pode ter promovido uma fermentação adequada, o que contribuiu para que não houvesse diferença no consumo de MS entre os tratamentos. Como pode ser observado na Tabela 5, os valores de $\mathrm{pH}$ e as concentrações de amônia ruminal em todos os tratamentos e horários avaliados ficaram dentro da faixa sugerida por diversos autores (WERNERBACH FILHO, et al. 2006; RODRIGUES et al. 2011) como adequados para que não limitasse a fermentação e a adequada degradação da fibra.

Tabela 3. Consumos médios diários em função dos tratamentos

\begin{tabular}{lcrrrrr}
\hline \multirow{2}{*}{ Item } & \multicolumn{5}{c}{ Tratamentos } \\
\cline { 2 - 5 } & $\begin{array}{c}\text { Silagem } \\
\text { Sorgo }\end{array}$ & $\begin{array}{c}\text { Silagem } \\
\text { Girassol }\end{array}$ & $\begin{array}{c}\text { Feno de } \\
\text { Leucena }\end{array}$ & $\begin{array}{r}\text { Feno de } \\
\text { Guandu }\end{array}$ & $\begin{array}{r}\text { Feno de } \\
\text { Elefante }\end{array}$ & \\
\hline CMS (kg/dia) & $0,930^{\mathrm{a}}$ & $0,894^{\mathrm{a}}$ & $1,047^{\mathrm{a}}$ & $0,977^{\mathrm{a}}$ & $0,991^{\mathrm{a}}$ & 12,29 \\
CMS (\%PV) & $2,900^{\mathrm{a}}$ & $2,820^{\mathrm{a}}$ & $3,300^{\mathrm{a}}$ & $3,070^{\mathrm{a}}$ & $3,170^{\mathrm{a}}$ & 13,33 \\
CMS (g/kg $\left.{ }^{0,75}\right)$ & $69,060^{\mathrm{a}}$ & $67,020^{\mathrm{a}}$ & $78,910^{\mathrm{a}}$ & $72,880^{\mathrm{a}}$ & $75,050^{\mathrm{a}}$ & 13,06 \\
CMO (kg/dia) & $0,793^{\mathrm{a}}$ & $0,744^{\mathrm{a}}$ & $0,893^{\mathrm{a}}$ & $0,837^{\mathrm{a}}$ & $0,832^{\mathrm{a}}$ & 12,00 \\
CPB (kg/dia) & $0,116^{\mathrm{a}}$ & $0,103^{\mathrm{a}}$ & $0,148^{\mathrm{a}}$ & $0,123^{\mathrm{a}}$ & $0,114^{\mathrm{a}}$ & 16,15 \\
CEE (kg/dia) & $0,016^{\mathrm{b}}$ & $0,046^{\mathrm{a}}$ & $0,160^{\mathrm{b}}$ & $0,022^{\mathrm{b}}$ & $0,017^{\mathrm{b}}$ & 35,78 \\
CFDN (kg/dia) & $0,369^{\mathrm{ab}}$ & $0,328^{\mathrm{b}}$ & $0,427^{\mathrm{ab}}$ & $0,419^{\mathrm{ab}}$ & $0,461^{\mathrm{a}}$ & 12,49 \\
CFDN (\%PV) & $1,150^{\mathrm{a}}$ & $1,030^{\mathrm{a}}$ & $1,360^{\mathrm{a}}$ & $1,310^{\mathrm{a}}$ & $1,470^{\mathrm{a}}$ & 13,86 \\
CCHT (kg/dia) & $0,717^{\mathrm{a}}$ & $0,651^{\mathrm{a}}$ & $0,787^{\mathrm{a}}$ & $0,756^{\mathrm{a}}$ & $0,756^{\mathrm{a}}$ & 11,38 \\
CCNF (kg/dia) & $0,346^{\mathrm{a}}$ & $0,315^{\mathrm{a}}$ & $0,360^{\mathrm{a}}$ & $0,337^{\mathrm{a}}$ & $0,294^{\mathrm{a}}$ & 12,83 \\
CNDT (kg/dia) & $0,618^{\mathrm{a}}$ & $0,574^{\mathrm{a}}$ & $0,585^{\mathrm{a}}$ & $0,587^{\mathrm{a}}$ & $0,544^{\mathrm{a}}$ & 11,97 \\
\hline
\end{tabular}

*Consumo de matéria seca (CMS), consumo matéria orgânica (CMO), consumo de proteína bruta (CPB), consumo de extrato etéreo (CEE), consumo de fibra em detergente neutro (CFDN), consumo de carboidratos totais (CCHT), consumo de carboidratos não fibrosos (CCNF) e consumo de nutrientes digestíveis totais (CCNDT).

Médias seguidas de letras distintas na mesma linha diferem entre si $(\mathrm{P}<0,01)$ pelo Teste de Tukey.

Os consumos de $\mathrm{MO}, \mathrm{PB}, \mathrm{CHT}, \mathrm{CNF}$ e NDT não diferiram entre os tratamentos ( $\mathrm{P}>0,01)$, cujas médias foram de 0,819 ; 0,$120 ; 0,733 ; 0,330$ e $0,581 \mathrm{~kg} / \mathrm{dia}$, respectivamente. Como houve pouca alteração na composição da dieta, com exceção de PB, EE e FDN, os consumos desses nutrientes seguiram o mesmo comportamento do consumo de MS. Entretanto, houve diferença $(\mathrm{P}<0,01)$ no consumo de EE quando se utilizou silagem de girassol em relação à silagem de sorgo e aos fenos. Isso pode ser justificado devido o teor de EE da silagem de girassol ter sido superior aos demais volumosos (Tabela 1). Esse 
maior consumo de EE no tratamento com silagem de girassol, provavelmente, não alterou o teor e o consumo de NDT das dietas em função da sua pequena magnitude (46g).

A silagem de girassol apresentou baixo teor de matéria seca $(21,34 \%)$, o que poderia afetar o consumo de matéria seca, porém, esse comportamento não foi observado. Como discutido anteriormente, a colheita foi realizada precocemente em virtude do ataque de pássaros. Por outro lado, Borgatti et al. (2005) afirmam que a principal limitação da conservação da cultura de girassol, pelo processo de ensilagem, é o baixo teor de matéria seca próximo ao momento do corte, em torno de $24 \%$. Com relação ao consumo de FDN (g/dia) foi observada superioridade $(\mathrm{P}<0,01)$ para o feno de capim-elefante em relação à silagem de girassol e semelhança para os demais volumosos, apresentada média de $0,400 \mathrm{~kg} / \mathrm{dia}$. Isso pode ser explicado devido ao maior teor de FDN presente no feno de capimelefante. Para o consumo de FDN $(\% \mathrm{PV})$ não houve diferença $(\mathrm{P}>0,01)$ entre os tratamentos, cuja média foi de $1,26 \% \mathrm{PV}$.

É importante ressaltar que foi baixa a proporção de alimentos concentrados nas dietas, além da inclusão de quantidades expressivas de ureia. Ao se considerar que o concentrado utilizado foi apenas o farelo de soja pode-se inferir que o maior aporte energético das dietas foi proveniente dos CNF da palma. Segundo Ferreira (2005), a palma forrageira, embora considerada um volumoso, apresenta baixos níveis de carboidratos fibrosos (FDN e FDA) e altos teores de carboidratos nãofibrosos, o que a caracteriza um alimento energético.

Os teores de NDT das dietas experimentais foram de 66,$5 ; 64,2 ; 55,9$; 60,1 e $54,9 \%$ para silagem de sorgo, silagem de girassol, fenos de leucena, guandu e capim-elefante, respectivamente. Foram avaliados outros experimentos com palma forrageira associada a outros volumosos e com níveis de inclusão de concentrados bem superior ao deste experimento, e foi observado que os níveis de energia (NDT) das dietas foram semelhantes ao encontrado neste trabalho. Véras et al. (2005) em experimento com ovinos, utilizaram farelo de palma ( $0 \%$ a $28,3 \%$ ) em substituição ao farelo de milho, feno de tifton e concentrado, e encontraram NDT das dietas que variaram de 51,35 a $62,88 \%$. Araújo et al. (2004) ao trabalharem com palma, capim elefante e farelo de soja $(21,5 \%)$ na alimentação de vacas em lactação, obtiveram dietas que variaram de 54,69 a $61,00 \%$ de NDT. Bispo et al. (2007) ao utilizarem palma (zero a 56\%) em substituição ao feno de capim elefante, fubá de milho $(17,28$ a $20 \%$ ) e farelo de soja (15 a $17,72 \%$ ) verificaram valores de NDT das dietas que variaram de 61,84 a $67,45 \%$.

A digestibilidade da matéria seca para a dieta com silagem de sorgo foi superior $(\mathrm{P}<0,01)$ quando comparada às com fenos de leucena e capim elefante, porém semelhante à silagem de girassol e ao feno de guandu (Tabela 4). Essa diferença pode ser justificada, em parte, pelos maiores níveis de lignina e fibra em detergente ácido, componentes tipicamente mais relacionados com a digestibilidade, presentes nos fenos (Tabelas 1 e 2). A lignina é um constituinte da célula vegetal de baixa ou nula digestibilidade, e apresenta influência sobre a digestibilidade da MS, da fibra bruta, da celulose e hemicelulose. Considerada como o principal fator limitante da digestibilidade em forragens (LAUNCHBAUGH et al., 2001), a lignina tem sua proporção aumentada à medida que a planta amadurece, o que diminui a porção mais digestível e, 
Rev. Bras. Saúde Prod. Anim., Salvador, v.13, n.2, p.444-456 abr./jun., 2012 http://www.rbspa.ufba.br ISSN 15199940

consequentemente, a disponibilidade de energia para o animal.

Vale ressaltar que os fenos de leucena e de guandu, foram confeccionados quando as plantas já haviam passado do ponto de frutificação e que foram usados também os talos das plantas. Segundo Gama et al.(2009) a lignificação das forragens de leguminosas lenhosas ocorre principalmente nas hastes e não nas folhas.

Tabela 4. Coeficiente de digestibilidade aparente dos nutrientes em função dos tratamentos

\begin{tabular}{ccccccc}
\hline \multirow{2}{*}{$\begin{array}{c}\text { Item } \\
(\%)\end{array}$} & $\begin{array}{c}\text { Silagem de } \\
\text { Sorgo }\end{array}$ & $\begin{array}{c}\text { Silagem de } \\
\text { Girassol }\end{array}$ & $\begin{array}{c}\text { Feno de } \\
\text { Leucena }\end{array}$ & $\begin{array}{c}\text { Feno de } \\
\text { Guandu }\end{array}$ & $\begin{array}{c}\text { Feno de } \\
\text { Elefante }\end{array}$ & \multicolumn{1}{c}{$\begin{array}{c}\text { CV } \\
(\%)\end{array}$} \\
\hline DMS & $68,66^{\mathrm{a}}$ & $62,63^{\mathrm{ab}}$ & $58,17^{\mathrm{b}}$ & $61,53^{\mathrm{ab}}$ & $57,02^{\mathrm{b}}$ & 5,34 \\
DMO & $70,71^{\mathrm{a}}$ & $64,30^{\mathrm{a}} \mathrm{b}$ & $58,84^{\mathrm{b}}$ & $63,15^{\mathrm{ab}}$ & $58,25^{\mathrm{b}}$ & 6,02 \\
DPB & $71,55^{\mathrm{a}}$ & $66,78^{\mathrm{a}}$ & $61,93^{\mathrm{a}}$ & $66,96^{\mathrm{a}}$ & $69,38^{\mathrm{a}}$ & 6,37 \\
DEE & $36,57^{\mathrm{ab}}$ & $70,68^{\mathrm{a}}$ & $18,02^{\mathrm{b}}$ & $33,36^{\mathrm{ab}}$ & $26,05^{\mathrm{b}}$ & 42,53 \\
DFDN & $57,09^{\mathrm{a}}$ & $45,37^{\mathrm{ab}}$ & $37,23^{\mathrm{b}}$ & $44,42^{\mathrm{b}}$ & $43,25^{\mathrm{b}}$ & 10,54 \\
DCHT & $73,63^{\mathrm{a}}$ & $66,32^{\mathrm{ab}}$ & $61,86^{\mathrm{b}}$ & $66,44^{\mathrm{ab}}$ & $60,12^{\mathrm{b}}$ & 6,47 \\
DCNF & $91,04^{\mathrm{a}}$ & $86,64^{\mathrm{a}}$ & $91,24^{\mathrm{a}}$ & $92,36^{\mathrm{a}}$ & $86,55^{\mathrm{a}}$ & 3,40 \\
\hline
\end{tabular}

*Digestibilidade da matéria seca (DMS), digestibilidade da matéria orgânica (DMO), digestibilidade da proteína bruta (DPB), digestibilidade do extrato etéreo (DEE), digestibilidade da fibra em detergente neutro (DFDN), digestibilidade dos carboidratos totais (DCHT) e digestibilidade dos carboidratos não fibrosos (DCNF).

Médias seguidas de letras distintas na mesma linha diferem entre si $(\mathrm{P}<0,01)$ pelo Teste de Tukey.

Para as digestibilidades aparentes da $\mathrm{PB}$ e CNF não foi observada diferença $(\mathrm{P}>0,01) \quad$ entre os tratamentos, cujas médias foram 67,32 e $89,56 \%$, respectivamente. Já para as digestibilidades da MO, EE, FDN e CHT observa-se, em geral, uma superioridade $(\mathrm{P}<0,01)$ da associação da silagem de sorgo com a palma comparada à associação com os fenos, com valores médios de 63,$05 ; 36,93 ; 45,47$ e $65,67 \%$ respectivamente. Provavelmente, o teor de lignina (Tabela 1) nos alimentos influenciou a digestibilidade da FDN, pois a proporção dos constituintes da FDN (proporção de hemicelulose, celulose e lignina) limita a digestão dos polissacarídeos da parede celular no rúmen (JUNG \& ALLEN, 1995).
Não foi observada diferença significativa $(\mathrm{P}>0,01)$ para os valores de $\mathrm{pH}$ para os tratamentos nos diferentes tempos de coleta, com média de 7,04 (Tabela 5). Esse valor está na faixa ideal de $\mathrm{pH}$ para digestão da fibra situada entre $(6,7$ e 7,1$)$, sugerido por diversos autores. Segundo Hoover \& Stokes (1991), as bactérias do rúmen são adaptadas para se desenvolverem em um meio com $\mathrm{pH}$ de 5,5 a 7,0 .

$\mathrm{O} \mathrm{pH}$ é influenciado pelo tipo de alimentação consumida e sua estabilização é devida em grande parte à saliva, que possui alto poder tamponante (VAN SOEST, 1994). Neste trabalho, houve um equilíbrio entre os carboidratos fibrosos (FDN) e CNF nas dietas, pois, os volumosos 
Rev. Bras. Saúde Prod. Anim., Salvador, v.13, n.2, p.444-456 abr./jun., 2012 http://www.rbspa.ufba.br ISSN 15199940

associados à palma proporcionaram nível de fibra fisicamente efetiva que, provavelmente, resultou numa melhor ruminação, o que estimulou a produção de saliva, e assim mantiveram-se as condições normais de saúde ruminal. A fibra fisicamente efetiva é a fração do alimento que irá estimular a atividade mastigatória e ruminatória, o que aumenta o fluxo salivar com a produção de produtos tamponantes e fermentativos que auxiliam na prevenção da depressão do consumo de matéria seca, motilidade ruminal, produção microbiana e na digestibilidade da fibra (ALLEN, 1997).

Tabela 5. Valores de pH e concentração de amônia ${ }^{1}$ em função dos tratamentos

\begin{tabular}{lccccrr}
\hline & \multicolumn{5}{c}{ Tratamentos } & \\
\cline { 2 - 5 } Item & $\begin{array}{c}\text { Silagem } \\
\text { Sorgo }\end{array}$ & $\begin{array}{c}\text { Silagem } \\
\text { Girassol }\end{array}$ & $\begin{array}{c}\text { Feno de } \\
\text { Leucena }\end{array}$ & $\begin{array}{c}\text { Feno de } \\
\text { Guandu }\end{array}$ & $\begin{array}{c}\text { Feno de } \\
\text { Capim } \\
\text { Elefante }\end{array}$ & CV(\%) \\
\hline pH (0 h) & 7,50 & 7,62 & 7,52 & 7,52 & 7,50 & 1,36 \\
pH (2 h) & 6,90 & 6,90 & 6,84 & 6,94 & 6,88 & 2,30 \\
pH (4 h) & 6,74 & 6,78 & 6,86 & 6,90 & 6,82 & 1,65 \\
pH (6 h) & 6,92 & 6,92 & 6,80 & 7,02 & 6,96 & 1,99 \\
\hline pH (Média)* & 7,02 & 7,06 & 7,01 & 7,10 & 7,04 & 1,42 \\
\hline $\mathrm{NH}_{3}(0$ h) & 10,15 & 10,29 & 11,34 & 8,96 & 9,87 & 21,35 \\
$\mathrm{NH}_{3}(2$ h) & 17,01 & 20,79 & 24,08 & 27,23 & 17,08 & 27,67 \\
$\mathrm{NH}_{3}(4$ h) & 10,08 & 10,71 & 13,30 & 13,37 & 7,35 & 30,18 \\
$\mathrm{NH}_{3}(6$ h) & 8,75 & 7,35 & 7,00 & 8,40 & 7,28 & 53,03 \\
\hline $\mathrm{NH}_{3}$ (Média)* & 11,50 & 12,29 & 13,93 & 14,49 & 10,40 & 14,91 \\
\hline
\end{tabular}

Concentração de amônia $\left(\mathrm{NH}_{3}\right)$ no líquido ruminal em $\mathrm{mg} / 100 \mathrm{~mL}$.

*Não houve diferença entre si $(\mathrm{P}<0,01)$ pelo Teste de Tukey.

A palma apresenta teores consideráveis de pectina, que de acordo com Van Soest (1994), apesar de rapidamente fermentável no rúmen, gera acetato como produto final, como ocorre com a fermentação da celulose. Muller \& Prado (2004) concluíram que a pectina possui um tipo de fermentação favorável, sem a produção de ácido lático, que ajuda a manter um ambiente ruminal favorável. Somado a esse fato, a oferta da dieta em forma de ração completa pode ter contribuído na manutenção do $\mathrm{pH}$, pois, segundo Pessoa et al. (2005) o uso de rações completas possibilita um padrão mais constante de fermentação no rúmen.
Com relação à concentração de amônia ruminal $\left(\mathrm{N}-\mathrm{NH}_{3}\right)$, não foi observada diferença significativa $(\mathrm{P}>0,01)$ para os tratamentos nos diferentes tempos de coleta, com média de $12,52 \mathrm{mg} / 100 \mathrm{~mL}$, superiores aos valores mínimos de 3,3 e $8,0 \mathrm{mg} / 100 \mathrm{~mL}$, sugeridos por Hoover (1986) como necessários para adequado crescimento microbiano e digestão da MO no rúmen, respectivamente (Tabela 5). Muitos autores defendem a existência de concentrações mínimas de $\mathrm{N}-\mathrm{NH}_{3}$ para que não limite a fermentação e a adequada degradação da fibra. Satter \& Slyter (1974) recomendam de 2 a $5 \mathrm{mg}$ de $\mathrm{N}-\mathrm{NH}_{3} / 100 \mathrm{~mL}$ de líquido ruminal e Mehrez et al. (1977), de 19 a 23mg de N$\mathrm{NH}_{3} / 100 \mathrm{~mL}$ de líquido ruminal. 
A associação de palma forrageira com silagens e fenos não altera o consumo de matéria seca e energia, o $\mathrm{pH}$ e amônia ruminais. De um modo geral, a digestibilidade aparente dos diversos nutrientes é superior para a associação das silagens com palma em relação aos fenos.

Dessa forma, silagens de sorgo e girassol e fenos de leucena, guandu e de capim elefante associados à palma forrageira apresentam-se como uma boa alternativa alimentar para ovinos na região semiárida do Nordeste brasileiro, o que contribui para o aumento na produtividade desses animais $\mathrm{e}$ melhoria de vida para os criadores dessa região.

\section{REFERÊNCIAS}

ALLEN, M.S. Relationship between fermentation acid production in the rumen and requirement for physically effective fiber. Journal of Dairy Science, v.80, n.7, p.1447-1462, 1997.

BISPO, S.V.; FERREIRA, M.A.; VÉRAS, A.S.C.; BATISTA, A.M.; PESSOA, R.A.S.; BLEUEL, M.P. Palma forrageira em substituição ao feno de capim-elefante. Efeito sobre consumo, digestibilidade e características de fermentação ruminal em ovinos. Revista Brasileira de Zootecnia, v.36, n.6, p.1902-1909, 2007.

BORGATTI, L.M.O.; RODRIGUES, P.H.M; ALMEIDA, T.F.; MEYER, M. Valor Nutritivo da Silagem de Girassol Inoculada com Bactérias Ácido-Láticas. Revista Brasileira de Zootecnia, v.34, n.1, p.340-344, 2005.
CRUZ, M.C.S.; VÉRAS, A.S.C.; FERREIRA, M.A.; BATISTA, A.M.V.; SANTOS, D.C.; COELHO, M.I.S. Balanço de nitrogênio e estimativas de perdas endógenas em vacas lactantes alimentadas com dietas contendo palma forrageira e teores crescentes de uréia e mandioca. Acta Scientiarum Animal Sciences, v.28, n.1, p.47-56, 2006.

CABRAL, L.S.; VALADARES FILHO, S.C.; DETMANN, E.; ZERVOUDAKIS, J.T.; SOUZA, A.L.; VELOSO, R.G. Eficiência microbiana e parâmetros ruminais em bovinos alimentados com dietas à base de volumosos tropicais. Revista Brasileira de Zootecnia, v.37, n.5, p.919-925, 2008.

DETMANN, E.; PAULINO, M.F.; ZERVOUDAKIS, J.T.;VALADARES FILHO, S.C., EUCLYDES, R.F.; LANA, R.P.; QUEIROZ, D.S. Cromo e indicadores internos na determinação do consumo de novilhos mestiços suplementados a pasto. Revista

Brasileita de Zootecnia, v.30, n.5, p.1600-1609, 2001.

\section{FERREIRA, M.A. Palma forrageira na alimentação de bovinos leiteiros.}

Recife: UFRPE, 2005.

FERREIRA, M.A.; SILVA, F.M.; BISPO, S.V.; AZEVEDO, M. Estratégias na suplementação de vacas leiteirasno semi-árido do Brasil. Revista Brasileira de Zootecnia, v.38, p.322-329, 2009. Supl.

GAMA, T.C. M.; ZAGO, V.C.P.; N.; M.L.F.; LAURA, V.A.; VOLPE, E.; MORAIS, M. G. Composição bromatológica, digestibilidade in vitro e produção de biomassa de leguminosas forrageiras lenhosas cultivadas em solo arenoso. Revista Brasileira de Saúde e Produção Animal [Online], v.10, n.3, p.560-572, 2009. 
Rev. Bras. Saúde Prod. Anim., Salvador, v.13, n.2, p.444-456 abr./jun., 2012 http://www.rbspa.ufba.br ISSN 15199940

HALL, M.B.; AKINYODE, A.

Cottonseed hulls: working with a novel fiber source. In: ANNUAL FLORIDA RUMINANT NUTRITION

SYMPOSIUM, 11., 2000, Gainesville. Proceedings... Gainesville, 2000. p.179-186.

HOOVER, W.H.; STOKES, S.R. Balancing carbohydrates and proteins for optimium rumen microbial yield. Journal of Dairy Science, v.74, n.10, p.3630-344, 1991.

HOOVER, W.H. Chemical factores involved in ruminal fiber digestion.

Journal of Dairy Science, v.69, n.10, p.2755-2766, 1986.

JUNG, H.G.; ALLEN, S.

Characteristics of plant cell walls affecting intake and digestibility of forages by ruminants. Journal of Dairy Science, v.73, n.9, p.2774-2790, 1995.

LAUNCHBAUGH, K.L.; PROVENZA, F.D.; ROPP, J. Understanding herbivore response to anti-quality factors in forages. Journal of Range

Management, v.54, p.431-440, 2001.

MEHREZ, A.Z.; ORSKOV, E.R.; McDONALD, I. Rates of rumen fermentation in relation to ammonia concentration. British Journal Nutrition, v.38, n.3, p.437-443, 1977.

MENEZES, D.R.; ARAÚJO, G.G.L.; OLIVEIRA, R.L.; BAGALDO, A.R.; SILVA, T.M. Ingestão voluntária por ovinos submetidos a rações com coproduto de vitivinícolas desidratado.

Revista Brasileira de Saúde e Produção Animal [Online], v.9, n.1, p.57-63, 2008.
MULLER, M; PRADO, I.N.

Metabolismo da pectina em animais ruminantes. Uma revisão. Revista Varia Scientia, v.4, n.8, p.45-56, 2004.

NATIONAL RESEARCH COUNCILNRC. Nutrient requeriments of the dairy cattle. 7.ed. Washigton, DC: National Academy Press, 2001. 381p.

PESSOA, R.A.S.; FERREIRA, M.A.; LIMA, L.E. Vacas leiteiras submetidas a diferentes estratégias alimentares. Digestibilidade e balanço de energia. Acta Scientiarum Animal Science, v.27, n.2, p.253-260, 2005.

RODRIGUES, G.H.; SUSIN, I.; PIRES, A.V.; NUSSIO, L.G.; GENTIL, R.S.; FERREIRA, E.M.; BIEHL, M.V.; RIBEIRO, M.F. Desempenho, características da carcaça, digestibilidade aparente dos nutrientes, metabolismo de nitrogênio e parâmetros ruminais de cordeiros alimentados com rações contendo polpa cítrica úmida semidespectinada e/ou polpa cítrica desidratada. Revista Brasileira de Zootecnia, v.40, n.10, p.2252-2261, 2011.

SATTER, L.D.; SLYTER, L.L. Effect of ammonia concentration on rumen microbial protein production in vitro. British Journal Nutrition, v.32, n.1, p.199-208, 1974.

SILVA, C.C.F.; SANTOS, L.C. Palma forrageira (Opuntia Fícus-Indica Mill) como alternativa na alimentação de ruminantes. Revista Eletrônica de Veterinária, v.7, n.10, p,1-13, 2006.

SILVA, D.J.; QUEIROZ, A.C. Análise de alimentos: métodos químicos e biológicos. 3.ed. Viçosa: Universidade Federal de Viçosa, 2002, 253p. 
Rev. Bras. Saúde Prod. Anim., Salvador, v.13, n.2, p.444-456 abr./jun., 2012 http://www.rbspa.ufba.br ISSN 15199940

UNIVERSIDADE FEDERAL DE VIÇOSA - UFV. - Sistema de Análises Estatísticas e Genéticas - SAEG. Versão 8.0. Viçosa, MG, 2001. 150p.

VAN SOEST, P.J. Nutritional ecology of the ruminants. 2.ed. Ithaca: Cornell University Press, 1994. 476p.

VÉRAS, R.M.L.; FERREIRA, M.A.; CAVALCANTI, C.V.A.; VERAS, A.S.C.; CARVALHO, F.F.R., SANTOS, G.R.A.; ALVES, K.S.; MAIOR JUNIOR, R.J.S. Substituição do Milho por Farelo de Palma Forrageira em Dietas de Ovinos em Crescimento. Desempenho. Revista Brasileira de Zootecnia, v.34, n.1, p.249-256, 2005.
WERNERSBACH FILHO, H.L.; CAMPOS, J.M.S.; ASSIS, A.J.; VALADARES FILHO, S.C.; QUEIROZ, A.C.; VALADARES, R.F.D.; LANA, R.P. Variáveis ruminais, concentração de uréia plasmática e excreções urinárias de nitrogênio em vacas leiteiras alimentadas com concentrado processado de diferentes formas.

Revista Brasileira de Zootecnia, v.35, n.3, p.1236-1241, 2006.

Data de recebimento: 08/06/2011

Data de aprovação: 19/04/2012 